\title{
Changes in bowel habits after laparoscopic sleeve gastrectomy
}

\author{
Petr Ostruszka, Petr Vávra, Lubomír Tulinský, Peter Ihnát \\ Department of Surgical Studies, Faculty of Medicine, University of Ostrava, Ostrava, Czech Republic
}

Videosurgery Miniinv 2020; 15 (3): 469-477

DOI: https://doi.org/10.5114/wiitm.2019.89830

\begin{abstract}
Introduction: Bariatric surgery has a significant impact on dietary intake, weight loss, patient's metabolism and also on defaecation stereotypes.

Aim: To investigate changes in bowel habits of morbidly obese patients after laparoscopic sleeve gastrectomy (LSG). Material and methods: This was a prospective clinical cohort study conducted to assess changes in bowel habits after LSG in a single institution.

Results: In total, 124 patients were enrolled in the study (age $47.1 \pm 11.2$ years, body mass index (BMI) $44.3 \pm 6.8 \mathrm{~kg} /$ $\mathrm{m}^{2}$ ). The mean weight loss 6 months after LSG was $29.1 \pm 11.1 \mathrm{~kg}$; percentage excess weight loss was $56.2 \pm 20.4 \%$. Before surgery, $35.5 \%$ of patients had constipation and $6.5 \%$ of patients had faecal incontinence (FI). No correlation was found between rising level of $B M I$ and constipation or incontinence prevalence/severity. Data analysis has not confirmed increased prevalence/severity of postoperative constipation or incontinence 6 months after LSG. Out of the group of patients with preoperative constipation, clinically relevant improvement was noted in $45.5 \%$ of patients after the surgery. Among patients without constipation before surgery, impairment was noted in $21.2 \%$ of patients. Out of the group of patients with preoperative incontinence, improvement was found in $37.5 \%$ of patients; none of these patients reported clinically relevant impairment of incontinence symptoms.

Conclusions: The present study has not revealed increased prevalence/severity of postoperative constipation or anal incontinence 6 months after LSG. Our findings suggest that weight loss in patients after LSG might be associated with an improvement of constipation symptoms of individual patients.
\end{abstract}

Key words: defaecatory disorders, obesity, sleeve gastrectomy, constipation, faecal incontinence.

\section{Introduction}

Currently, bariatric surgery is the only effective therapy for morbidly obese patients, with sustained weight loss, improvement in comorbidities and positive effects on quality of life after the surgery [1, 2]. Laparoscopic sleeve gastrectomy (LSG) is a safe and effective bariatric operation which has rapidly gained popularity to become the most commonly performed bariatric procedure worldwide [3, 4].

Obesity is considered an important independent risk factor for pelvic floor disorders, including urinary incontinence, faecal incontinence and constipation
[5-7]. The association between obesity and urinary/ faecal incontinence has been clearly documented in the available literature $[8,9]$; the prevalence of constipation in obese patients is unclear and reports are often discordant $[6,10]$.

Bariatric surgery has a significant impact on dietary intake, weight loss, patient's metabolism and also on defaecation stereotypes. However, data regarding changes in bowel habits after bariatric surgery are very limited [7]. It has been reported that patients after malabsorptive procedures, such as biliopancreatic diversion (BPD) and Roux-en-Y gas-

\section{Address for correspondence}

Assist. Prof. Peter Ihnát MD, PhD, MBA, Department of Surgical Studies, Faculty of Medicine, University of Ostrava, 17. listopadu 1790,

70852 Ostrava, Czech Republic, e-mail: peterihnat@yahoo.com 
tric bypass (RYGB), experience diarrhoea and faecal incontinence more frequently compared to the situation before the operation [11-13]. On the other hand, restrictive procedures such as gastric band or LSG may predispose patients to constipation $[6,12,14]$.

\section{Aim}

To the best of our knowledge, there are only a few studies with very limited numbers of included patients investigating the prevalence and severity of defaecation disorders after LSG. The aim of the present study was to investigate changes in bowel habits of morbidly obese patients after LSG.

\section{Material and methods}

\section{Design and setting}

This was a prospective observational clinical cohort study designed to evaluate changes in bowel habits of obese patients after LSG. The study was conducted in the University Hospital Ostrava, Czech Republic. All patients with morbid obesity undergoing LSG at the University Hospital Ostrava between $1^{\text {st }}$ January 2012 and $31^{\text {st }}$ December 2017 were assessed for study eligibility. The study was approved by the ethics committee of the University Hospital Ostrava (FNO 339/2018) and was performed in accordance with the ethical standards of the Declaration of Helsinki (1964) and its subsequent amendments. Written informed consent was obtained from all included patients, and anonymity was ensured.

The inclusion criteria were ages 18-65 years, body mass index $(\mathrm{BMI}) \geq 40 \mathrm{~kg} / \mathrm{m}^{2}$ (or BMI $35-39 \mathrm{~kg} / \mathrm{m}^{2}$ with obesity-related comorbidities) and suitability for elective bariatric surgery. Exclusion criteria were a history of previous surgical procedures on the digestive system, serious neurological or psychiatric diseases, pharmacological treatment that may affect defaecation (e.g. antidepressants, opiates, anticholinergic drugs) and incomplete data regarding patients' follow-up.

\section{Surgical technique}

All operations were performed under general anaesthesia; the patient was placed in the supine, anti-Trendelenburg position. The 5-port technique with liver retractor was employed. The omental bursa was opened 4-6 cm proximal to the pylorus, proceeding superiorly to the angle of His, where the left crus was visualised. Gastroepiploic and short gastric vessels were sealed and divided just near the stomach wall. A $36 \mathrm{~F}$ orogastric bougie was placed and anchored to the pylorus to avoid stenosis. Green or gold $60 \mathrm{~mm}$ cartridges were used to staple and create the final sleeve shape stomach. If small bleeding from the staple line occurred, a bipolar electrocoagulation or clip was used (oversuturing of the staple line was not performed routinely). The resected stomach was removed via a $20 \mathrm{~mm}$ port; a drain was then placed along the staple line.

\section{Data collection}

All data were collected prospectively during the study. The anamnestic and demographic data of all study patients were recorded in a study database. Prior to surgery, all patients completed two validated questionnaires aimed at evaluating bowel habits - the Wexner Constipations Score (WCS) and the Cleveland Clinic Incontinence Score (CCIS) $[15,16]$. Postoperative complications were graded according to the Clavien-Dindo Classification [17]. After the surgery, the standard dietary protocol of study patients consisted of frequent small meals (4-6 meals per day), eating an adequate amount of protein, drinking sufficient amounts of fluids (avoiding carbonated beverages), and separating liquids from solids. Patients had also been advised to eat slowly with proper chewing, and to make an effort to eat a balanced diet and limit consumption of calorie-dense food and drinks [18].

Six months after LSG, the patients were invited to a follow-up visit, during which anthropometric parameters and changes in bowel habits were reassessed. The incidence and severity of constipation/ faecal incontinence were evaluated by re-administration of the WCS and CCIS questionnaires. The questionnaires were analyzed both for global scores and for selected item sub-scores. We considered abnormal a WCS $\geq 5$ and CCIS score $\geq 5$. For the purposes of the study, an improvement of the WCS and CCIS greater than $25 \%$ was considered clinically relevant.

\section{Statistical analysis}

The acquired data underwent analysis by means of descriptive statistics. The differences between the subgroups were tested using the $\chi^{2}$ test, Fisher's exact test and the Kruskal-Wallis rank test. For 
testing the differences before and 6 months after LSG, paired tests were used (test of symmetry and Wilcoxon signed-rank test). The statistical analysis was conducted using Stata version 15. A level of significance of $\alpha=0.05$ was considered statistically significant.

\section{Results}

In total, 149 patients underwent LSG at University Hospital Ostrava within the study period. Of these, $25(16.8 \%)$ patients were excluded due to the study design and exclusion criteria (Figure 1). One hundred twenty-four patients were enrolled in the study and underwent analysis.

\section{Demographic and clinical data}

The mean age of study patients was 47.1 \pm 11.23 years (mean \pm SD); there were $90(72.6 \%)$ women and $34(27.4 \%)$ men. The majority of patients (60.5\%) were preoperatively classified as ASA class II. The mean BMI before surgery was 44.3 $\pm 6.83 \mathrm{~kg} / \mathrm{m}^{2}$. Based on the value of BMI, the patients were divided into three study subgroups (Table I). The mean operative time was $74.2 \pm 23.63 \mathrm{~min}$; no additional operative procedure (such as cholecystectomy or appendectomy) was performed in our study patients. There were no intraoperative complications; postoperative complications were noted in $8(6.4 \%)$ patients. Out of these, $3(2.4 \%)$ com-

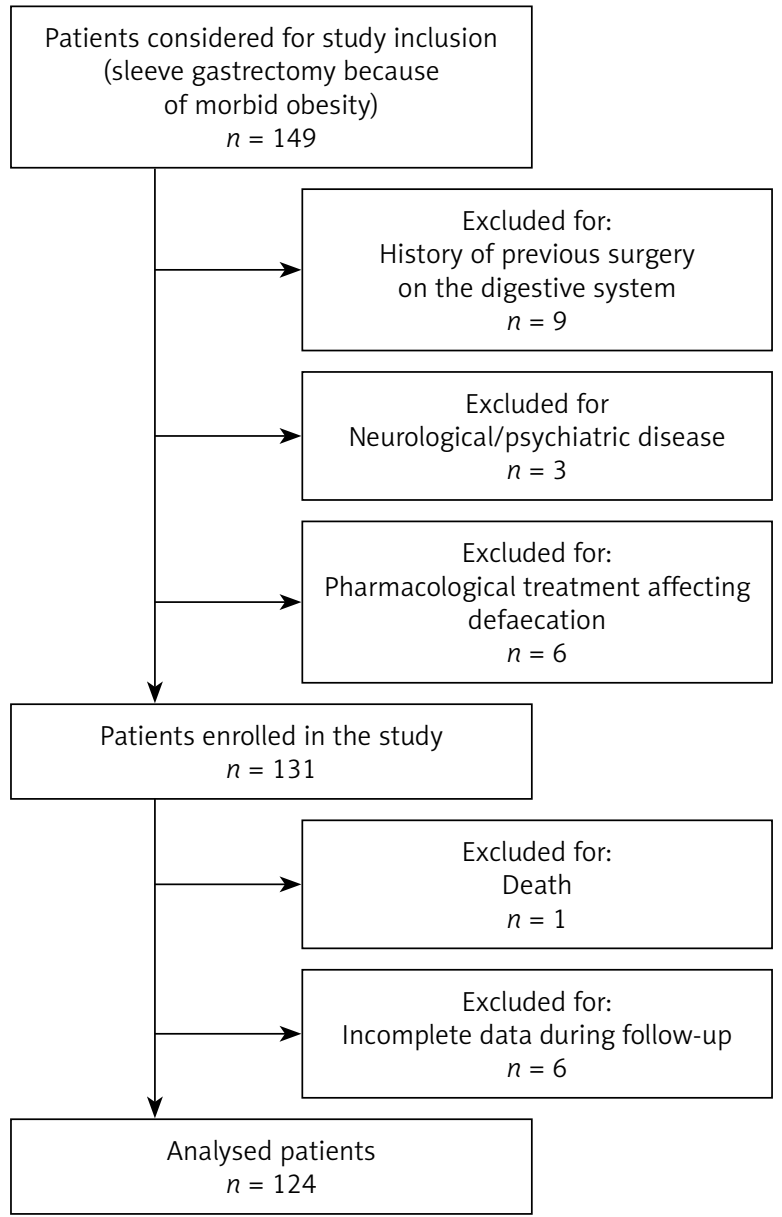

Figure 1. Study flow-chart diagram

Table I. Demographic and clinical data of study patients

\begin{tabular}{|c|c|c|c|c|}
\hline Parameter & $\begin{array}{c}\mathrm{BMI}<40 \mathrm{~kg} / \mathrm{m}^{2} \\
\quad(n=37)\end{array}$ & $\begin{array}{c}\text { BMI } 40-50 \mathrm{~kg} / \mathrm{m}^{2} \\
(n=61)\end{array}$ & $\begin{array}{c}\mathrm{BMI}>50 \mathrm{~kg} / \mathrm{m}^{2} \\
\quad(n=26)\end{array}$ & $\begin{array}{c}\text { Total } \\
(n=124)\end{array}$ \\
\hline Age, mean \pm SD [years] & $47.5 \pm 10.97$ & $46.8 \pm 11.64$ & $47.4 \pm 11.07$ & $47.1 \pm 11.23$ \\
\hline \multicolumn{5}{|l|}{ Gender, $n$ (\%): } \\
\hline Male & $11(29.7)$ & $14(22.9)$ & $9(34.6)$ & $34(27.4)$ \\
\hline Female & $26(70.3)$ & $47(77.1)$ & $17(65.4)$ & $90(72.6)$ \\
\hline $\mathrm{BMI}$, mean $\pm \mathrm{SD}\left[\mathrm{kg} / \mathrm{m}^{2}\right]$ & $37.5 \pm 1.46$ & $43.9 \pm 2.53$ & $55.0 \pm 4.82$ & $44.3 \pm 6.83$ \\
\hline \multicolumn{5}{|l|}{ ASA, $n(\%):$} \\
\hline I & $2(5.4)$ & $5(8.2)$ & $0(0.0)$ & $7(5.6)$ \\
\hline$\|$ & $24(64.9)$ & $40(65.6)$ & $11(42.3)$ & $75(60.5)$ \\
\hline III & $11(29.7)$ & $16(26.2)$ & $15(57.7)$ & $42(33.9)$ \\
\hline Weight loss, mean \pm SD [kg] & $23.3 \pm 7.45$ & $29.6 \pm 10.72$ & $36.5 \pm 11.85$ & $29.1 \pm 11.08$ \\
\hline Percentage excess weight loss (\%), mean \pm SD & $65.1 \pm 20.25$ & $55.4 \pm 19.56$ & $45.5 \pm 17.44$ & $56.2 \pm 20.42$ \\
\hline
\end{tabular}


plications were classified as grade I-II according to Clavien-Dindo and 5 (4.0\%) complications as grade III-IV. One patient died on the $11^{\text {th }}$ day after LSG because of acute postoperative respiratory failure.

\section{Weight loss}

The mean weight loss 6 months after LSG was $29.1 \pm 11.08 \mathrm{~kg}$. The differences in weight loss between study subgroups are presented in Table I. The percentage excess weight loss (\%EWL - calculated based on ideal body weight of BMI $25 \mathrm{~kg} / \mathrm{m}^{2}$ ) was $56.2 \pm 20.42 \%$ in our study group.

\section{Bowel habits before LSG}

Before surgery, 46 (37.1\%) study patients reported defaecation disorders according to the aforementioned scores (constipation, incontinence or mixed defaecation disorders). As shown in Table II, there were $44(35.5 \%)$ patients who had WCS $\geq 5$; only $2(1.6 \%)$ patients reported symptoms of severe constipation (WCS $\geq 15$ ). Symptoms of anal inconti- nence $(C C I S \geq 5)$ were found in $8(6.5 \%)$ patients before surgery. Detailed analysis of anal incontinence symptoms (occasional symptoms of anal incontinence for flatus, liquid stools or liquid + solid stools) revealed that almost half of the study patients (43.5\%) reported at least occasional incontinence for flatus (gas) before surgery. Mixed defaecation disorders (constipation and incontinence) were found in $6(4.8 \%)$ patients.

Data regarding the correlation between the level of $\mathrm{BMI}$ and the prevalence of defaecation disorders are presented in Table II. There were no statistically significant differences in prevalence of defaecation disorders between study subgroups.

\section{Bowel habits after LSG}

The number of patients with normal frequency of bowel motion (1-2 stools per 1-2 days) 6 months after LSG was lower in comparison with preoperative status, but the difference was not statistically significant $(59.7 \%$ vs. $70.2 \%, p=0.140)$. Detailed data

Table II. Bowel habits of study patients before surgery

\begin{tabular}{|c|c|c|c|c|c|}
\hline Parameter & $\begin{array}{c}\mathrm{BMI}<40 \mathrm{~kg} / \mathrm{m}^{2} \\
\quad(n=37)\end{array}$ & $\begin{array}{c}\text { BMI } 40-50 \mathrm{~kg} / \mathrm{m}^{2} \\
(n=61)\end{array}$ & $\begin{array}{l}\mathrm{BMI}>50 \mathrm{~kg} / \mathrm{m}^{2} \\
\quad(n=26)\end{array}$ & $P$-value & $\begin{array}{c}\text { Total } \\
(n=124)\end{array}$ \\
\hline \multicolumn{6}{|l|}{$\begin{array}{l}\text { Frequency of bowel motion, } \\
n(\%) \text { : }\end{array}$} \\
\hline $1-2$ stools per $1-2$ days & $25(67.6)$ & $42(68.8)$ & $20(76.9)$ & & $87(70.2)$ \\
\hline $2-3 \times$ per week & $8(21.6)$ & $17(27.9)$ & $5(19.2)$ & 0.551 & $30(24.2)$ \\
\hline$\leq 1$ per week & $4(10.8)$ & $2(3.3)$ & $1(3.9)$ & & $7(5.6)$ \\
\hline \multicolumn{6}{|l|}{$\begin{array}{l}\text { Wexner Constipation Score } \\
\text { (WCS): }\end{array}$} \\
\hline Mean \pm SD & $4.5 \pm 4.87$ & $4.1 \pm 3.65$ & $3.7 \pm 2.81$ & 0.969 & $4.1 \pm 3.89$ \\
\hline WCS $\geq 5, n(\%)$ & $13(35.1)$ & $20(32.8)$ & $11(42.2)$ & 0.696 & $44(35.5)$ \\
\hline \multicolumn{6}{|l|}{$\begin{array}{l}\text { Cleveland Clinic } \\
\text { Incontinence Score: }\end{array}$} \\
\hline Mean \pm SD & $1.3 \pm 1.72$ & $1.7 \pm 1.78$ & $1.2 \pm 1.58$ & 0.261 & $1.5 \pm 1.72$ \\
\hline CCIS $\geq 5, n(\%)$ & $2(5.4)$ & $5(8.2)$ & $1(3.8)$ & 0.802 & $8(6.5)$ \\
\hline \multicolumn{6}{|l|}{$\begin{array}{l}\text { Occasional symptoms of } \\
\text { anal incontinence, } n(\%) \text { : }\end{array}$} \\
\hline Liquid + solid stools & $2(5.4)$ & $2(3.3)$ & $1(3.8)$ & & $5(4.0)$ \\
\hline Liquid stools & $1(2.7)$ & $12(19.7)$ & $4(15.4)$ & 0.216 & $17(13.7)$ \\
\hline Flatus (gas) & $18(48.6)$ & $27(44.2)$ & $9(34.6)$ & & $54(43.5)$ \\
\hline $\begin{array}{l}\text { Mixed defaecation } \\
\text { disorders, } n(\%)\end{array}$ & $2(5.4)$ & $3(4.9)$ & $1(3.8)$ & 1.000 & $6(4.8)$ \\
\hline
\end{tabular}


regarding changes in bowel habits 6 months after LSG are presented in Table III. The mean postoperative WCS was comparable with preoperative WCS $(p=0.900)$. The number of patients with abnormal WCS (WCS $\geq 5$ ) after LSG was also similar to that of the preoperative status ( $36.3 \%$ vs. $35.5 \%, p=0.862$ ). Similarly, the mean CCIS score and number of patients with abnormal CCIS after LSG were comparable with preoperative status (the differences were not statistically significant).

Although statistical numbers (percentage, mean \pm SD) comparing bowel motion before and after surgery did not show significant differences, detailed analysis of individual patients' symptoms revealed significant changes in bowel habits after LSG (see below).

Out of the subgroup of patients with preoperative constipation (WCS $\geq 5$ ), clinically relevant improvement was noted in $45.5 \%$ of patients after the surgery (clinically relevant impairment in $22.7 \%$ of patients). Within the subgroup of patients without constipation before surgery (80 patients), impairment was noted in 17 (21.2\%) patients after LSG. Symptoms of severe constipation (WCS $\geq 15$ ) were not observed in any of our patients after the surgery.
Out of the subgroup of patients with preoperative incontinence (CCIS $\geq 5)$, clinically relevant improvement was found in 3 (37.5\%) patients; none of these patients reported impairment of incontinence symptoms. Within the subgroup of patients without incontinence before surgery (116 patients), impairment was noted in $6(5.2 \%)$ patients.

Patients with preoperative mixed defaecation disorders reported improvement of constipation and incontinence ( 2 patients), improvement in constipation (1 patient) or no clinically relevant changes (3 patients).

\section{Discussion}

Bariatric surgery presents the most effective form of sustained weight loss in patients with obesity $[1,3]$. Despite the significant clinical benefits of bariatric surgery, some patients are disappointed with the weight loss due to unrealistic expectations. Recently, Janik et al. proposed a predictive model for estimating BMI at 1 year after LSG. This tool allows one to set realistic expectations of weight loss after LSG. Once a realistic goal is set, the patient can be encouraged to accomplish it [19].

Table III. Changes in bowel habits 6 months after LSG

\begin{tabular}{|c|c|c|c|}
\hline Parameter & Before LSG & 6 months after LSG & $P$-value \\
\hline \multicolumn{4}{|l|}{ Frequency of bowel motion, $n(\%)$ : } \\
\hline $1-2$ stools per $1-2$ days & $87(70.2)$ & $74(59.7)$ & \\
\hline $2-3 \times$ per week & $30(24.2)$ & $36(29.0)$ & 0.140 \\
\hline$\leq 1$ per week & $7(5.6)$ & $14(11.3)$ & \\
\hline \multicolumn{4}{|l|}{ Wexner Constipation Score: } \\
\hline Mean \pm SD & $4.1 \pm 3.89$ & $4.2 \pm 3.77$ & 0.900 \\
\hline WCS $\geq 5, n(\%)$ & $44(35.5)$ & $45(36.3)$ & 0.862 \\
\hline \multicolumn{4}{|l|}{ CCIS: } \\
\hline Mean \pm SD & $1.5 \pm 1.72$ & $1.7 \pm 2.07$ & 0.149 \\
\hline $\mathrm{CCIS} \geq 5, n(\%)$ & $8(6.5)$ & $11(8.9)$ & 0.317 \\
\hline \multicolumn{4}{|c|}{ Occasional symptoms of anal incontinence, $n(\%)$ : } \\
\hline Liquid + solid stools & $5(4.0)$ & $3(2.4)$ & \\
\hline Liquid stools & $17(13.7)$ & $21(16.9)$ & 0.760 \\
\hline Flatus (gas) & $54(43.5)$ & $57(45.9)$ & \\
\hline Mixed defaecation disorders, $n(\%)$ & $6(4.8)$ & $7(5.6)$ & 0.776 \\
\hline
\end{tabular}


Although LSG presents the most commonly performed bariatric procedure worldwide, very little is known about changes in bowel habits of these patients after the surgery. Constipation affects $2-27 \%$ of the western population, but the relationship between obesity and constipation is still unclear [20]. Some authors reported no association between increasing BMI and constipation prevalence [21-23], while other authors found a higher rate of constipation in obese individuals $[24,25]$. Our study data confirmed that constipation presents a common problem in obese individuals $(37.1 \%$ of patients reported symptoms of constipation and reached WCS $\geq 5$ before surgery). However, no correlation between rising level of BMI and constipation prevalence/severity was found in our study group.

LSG changes the shape of the stomach, reduces its volume, and alters its vagal innervation and the quantity of secretory cells. Due to different mechanisms (increased gastric emptying and intestinal transit, changes in hormonal mechanisms, alterations in bile acids, etc.), LSG is not considered to be a pure restrictive bariatric procedure $[1,3]$. With regards to increased gastric emptying and intestinal transit in patients after LSG, increased prevalence of diarrhoea should be expected. The opposite is true; most available studies suggest increased prevalence of constipation after LSG [12, 26, 27].

In a retrospective study, El Labban et al. compared bowel habits of patients with extreme obesity 1 year after LSG (30 patients) and RYGB (30 patients). In patients after LSG, a significantly higher prevalence of constipation was found [12]. Sileri et al. investigated the prevalence of defaecatory disorders in 68 morbidly obese patients before and after LSG. The authors reported that the mean WCS score decreased from $3.7 \pm 3$ to $1.6 \pm 3$ and the mean CCIS score decreased from $10 \pm 8$ to $1 \pm 2$ in study patients 6 months after LSG. The authors therefore concluded that bariatric surgery reduces defaecatory disorders, mainly faecal incontinence, and these findings correlate with BMI reduction [6].

In a retrospective study consisting of 178 patients after LSG, Goldenshluger et al. reported constipation in $24.7 \%$ of patients 3 years after the surgery. The evaluation of postoperative defaecation disorders was done only by means of a posted self-constructed questionnaire 3 years after the surgery; prevalence of defaecation disorders before surgery and its changes after LSG were not investigated [28].
Our study did not show increased prevalence/severity of postoperative constipation 6 months after LSG. Out of the group of patients with normal bowel habits before surgery, clinically relevant impairment in terms of constipation was noted in $21.2 \%$ of patients after the surgery. A very important outcome of our study is that within the subgroup of patients with preoperative symptoms of constipation, clinically relevant improvement was noted in $45.5 \%$ of patients postoperatively.

The prevalence of $\mathrm{Fl}$ in an adult population is estimated from $4 \%$ to $19 \%$ and is highly dependent on the studied population, definition of incontinence and methods of its detection $[29,30]$. Obesity is a known risk factor for the development of Fl; epidemiological studies demonstrated almost twofold higher prevalence of $\mathrm{Fl}$ in obese patients compared to non-obese individuals [31-34]. In our study group, a relatively low prevalence of $\mathrm{Fl}$ preoperatively was recorded (only $6.5 \%$ of patients). However, up to $61.3 \%$ of our patients reported at least occasional incontinence of flatus or liquid stools.

LSG affected symptoms of incontinence of our study patients very insignificantly - the prevalence/ severity of Fl had not changed 6 months after the surgery. However, the number of our study patients with incontinence symptoms before LSG was too low to make any generalizations regarding the impact of LSG on incontinence symptoms. In contract to LSG, it has been reported that malabsorptive bariatric procedures (such as laparoscopic RYGB and BPD) are associated with an increased risk of diarrhoea, flatulence severity and worsening symptoms of faecal incontinence compared to the situation before surgery [11-13].

Potoczna et al. compared bowel habits of 290 patients at least 4 months after bariatric surgery (BPD, RYGB and $A G B$ ). In patients after BPD and RYGB, an increased frequency of loose stools (6.3\% vs. $40.5 \%)$ and diarrhoea (1.0\% vs. $17.5 \%)$ was noted after the surgery. Symptoms of constipation were more frequent in patients after AGB (21.3\% vs. $39.3 \%)$. The authors concluded that the observation period after bariatric surgery had no influence on overall results of bowel habits [11].

After malabsorptive bariatric procedures, longer alimentary limbs are associated with severe malabsorption and increased diarrhoea symptoms [35]. Restrictive procedures (such as AGB and LSG) do not alter the length and extent of absorption area of the small intestine. The postoperative risk of diarrhoea 
and associated incontinence is therefore much lower compared to malabsorptive procedures. Our study outcomes suggest that weight loss after LSG does not improve the prevalence/severity of FI. This is in accordance with the available literature, where most studies describe the positive effect of weight loss after bariatric surgery on urinary incontinence but not on faecal incontinence $[36,37]$. A recent meta-analysis revealed that more than half of obese patients reported improvement/resolution of urinary incontinence after bariatric surgery. The authors suggested that these data could make bariatric surgery a potentially useful strategy in the management of urinary incontinence in obese patients [38].

There is growing evidence suggesting that patients after bariatric surgery not only reduce the volume of food and their caloric intake, but also show changes in food preference [39]. Several changes have been described: reduced hunger, reduced preference for calorically dense foods with high sugar and high fat content, change of taste, altered secretion of gut hormones, alterations in the gut microbiota and bile acid levels/composition [39-41]. The mechanisms for the food preference changes after LSG may involve both unconditioned and conditioned effects; the decrease in high fat food and sweets suggests that bariatric procedures may influence cognitive choices of food. Changes in eating habits/food preference seem to significantly affect bowel habits of patients after LSG. However, further clinical studies on this topic are needed.

Diet is a key factor influencing the composition and function of the gut microbiota, with rapid alteration seen after short-term diet modification [42, 43]. In patients after LSG, enhanced faecal excretion of bile acids and non-esterified fatty acids has been observed. LSG improves the obesity-associated gut microbiota composition towards a lean microbiome, which plays an important role in nutrient absorption and the regulation of nutrient harvest [43]. Postoperative changes in the gut microbiota contribute to weight loss in patients after bariatric surgery and might have an influence on their bowel habits.

It has been demonstrated that LSG leads to weight loss by causing complex alterations in gastrointestinal physiology and changes not only gastric but also global intestinal function [44]. LSG significantly accelerates gastric emptying and intestinal motility with markedly reduced intestinal transit time of semisolids [44, 45]. Melissas et al. found in their study that although the meal reaches the terminal ileum faster (in patients after LSG), it arrives at the caecum later because caecal filling initiation is delayed [44]. The authors suggested that the delay is caused by postoperative changes in the function of the ileocaecal valve. Early and prolonged contact of food with the mucosa of the terminal ileum (earlier food entry and later exit) allows prolonged stimulation of intestinal $L$ cells producing incretins capable of ameliorating glycaemic control. It supports the hypothesis that neuroendocrine changes occurring after LSG alter gastrointestinal function and metabolic profile of the patient. Shortening of gastric emptying time, accelerated small bowel transit and delayed initiation of caecal filling may be important factors significantly influencing bowel habits of patients after LSG. However, further studies are needed to elucidate neuroendocrine changes taking place after LSG.

LSG can be associated with micronutrient deficiencies event if vitamin supplements are included in postsurgical protocols, vitamin $D$ deficiency being the most prevalent long-term nutritional deficiency [46]. Thiamine deficiency has been reported in $18 \%$ of patients after RYGB and in $25.7 \%$ of patients after LSG [47, 48]. According to available data, symptoms of constipation, dyspepsia and vomiting in bariatric patients might be caused by thiamine deficiency. Therefore, when a gastroenterologist sees a bariatric patient with symptoms of constipation, dyspepsia or vomiting, diagnosis of thiamine deficiency should be considered. Early identification and treatment with oral/parenteral thiamine in these patients should be launched [46-48].

This was a prospective observational study aimed at investigating changes in bowel habits of obese patients undergoing LSG. The strengths of the study include high homogeneity of the study group, standardized data-acquisition techniques, and precise assessment of bowel habits by means of validated scoring systems used at a fixed time point. To the best of our knowledge, this is the second largest study investigating bowel habits in patients after LSG. The study has several limitations: it was a cohort study with a limited number of patients, and defaecation disorders were examined only once after the surgery.

\section{Conclusions}

Our study did not reveal increased prevalence/ severity of postoperative constipation or anal incon- 
tinence 6 months after LSG. Our findings suggest that weight loss in patients after LSG might be associated with an improvement of constipation symptoms of individual patients. These outcomes potentiate the safety and effectiveness of LSG as primary bariatric surgery.

\section{Conflict of interest}

The authors declare no conflict of interest.

\section{References}

1. Bray GA, Frühbeck G, Ryan DH, et al. Management of obesity. Lancet 2016; 387: 1947-56.

2. Major P, Matłok M, Pędziwiatr M, et al. Quality of life after bariatric surgery. Obes Surg 2015; 25: 1703-10.

3. Baltasar A, Serra C, Perez N, et al. Laparoscopic sleeve gastrectomy: a multi-purpose bariatric operation. Obes Surg 2005; 15 $1124-8$

4. Våge V, Sande VA, Mellgren G, et al. Changes in obesity-related diseases and biochemical variables after laparoscopic sleeve gastrectomy: a two-year follow-up study. BMC Surg 2014; 14: 8

5. Delgado-Aros S, Locke GR, Camillieri M, et al. Obesity is associated with increased risk of gastrointestinal symptoms: a population-based study. Am J Gastroenterol 2004; 99: 1801-6.

6. Sileri P, Franceschilli L, Cadeddu F, et al. Prevalence of defaecatory disorders in morbidly obese patients before and after bariatric surgery. J Gastrointest Surg 2012; 16: 62-7.

7. Bharucha AE. Incontinence: an underappreciated problem in obesity and bariatric surgery. Dig Dis Sci 2010; 55: 2428-30.

8. Uustal Fornell E, Wingren G, Kjolhede P. Factors associated with pelvic floor dysfunction with emphasis on urinary and fecal incontinence and genital prolapse: an epidemiological study. Acta Obstet Gynecol Scand 2004; 83: 383-9.

9. Richter HE, Burgio KL, Clements RH, et al. Urinary and anal incontinence in morbidly obese women considering weight loss surgery. Obstet Gynecol 2005; 106: 1272-7.

10. Talley NJ, Quan C, Jones MP, Horowitz M. Association of upper and lower gastrointestinal tract szmptoms with body mass in dex in an Australian cohort. Neurogastroenterol Motil 2004; 16 413-9.

11. Potoczna N, Harfmann S, Steffen R, et al. Bowel habits after bariatric surgery. Obes Surg 2008; 18: 1287-96.

12. El Labban S, Safadi B, Olabi A. The effect of Roux-en-Y gastric bypass and sleeve gastrectomy surgery on dietary intake, food preferences, and gastrointestinal symptoms in post-surgical morbidly obese lebanese subjects: a cross-sectional pilot study. Obes Surg 2015; 25: 2393-9.

13. Roberson EN, Gould JC, Wald A. Urinary and fecal incontinence after bariatric surgery. Dig Dis Sci 2010; 55: 2606-13.

14. Afshar S, Kelly SB, Seymour K, et al. The effects of bariatric procedures on bowel habit. Obes Surg 2016; 26: 2348-54.

15. Agachan F, Chen T, Pfeifer J, et al. A constipation scoring system to simplify evaluation and management of constipated patients. Disc Colon Rectum 1996; 39: 681-5.
16. Jorge JM, Wexner SD. Etiology and management of fecal incontinence. Dis Colon Rectum 1993; 36: 77-97.

17. Dindo D, Demartines N, Clavien PA. Classification of surgical complications: a new proposal with evaluation in a cohort of 6336 patients and results of a survey. Ann Surg 2004; 240: 205-13.

18. Sherf Dagan S, Goldenshluger A, Globus I, et al. Nutritional recommendations for adult bariatric surgery patients: clinical practice. Adv Nutr 2017; 8: 382-94.

19. Janik MR, Rogula TG, Mustafa RR, et al. Setting realistic expectations for weight loss after laparoscopic sleeve gastrectomy. Videosurgery Miniinv 2019; 14: 415-9.

20. Foxx-Orenstein AE, McNally MA, Odunsi ST. Update on constipation: one treatment does not fit all. Cleve Clin J Med 2008; 75: 813-24.

21. Zonča P, Bužga M, Ihnát P, et al. Retroperitoneoscopic adrenalectomy in obese patients: is it suitable? Obes Surg 2015; 25: 1203-8.

22. Pourhoseingholi MA, Kaboli SA, Pourhoseingholi A, et al. Obesity and functional constipation: a community-based study in Iran. J Gastrointest Liver Dis 2009; 18: 151-5.

23. Eslick GD, Talley NJ. Prevalence and relationship between gastrointestinal symptoms among individuals of different body mass index: a population-based study. Obes Res Clin Pract 2016; 10: 143-50.

24. Pecora P, Suraci C, Antonelli M, et al. Constipation and obesity: a statistical analysis. Boll Soc Ital Biol Sper 1981; 57: 2384-8.

25. Eslick GD. Prevalence and epidemiology of gastrointestinal symptoms among normal weight, overweight, obese and extremely obese individuals. Gastroenterol Clin North Am 2010; 39: 9-22.

26. Innát P, Martínek L, Mitták M, et al. Quality of life after laparoscopic and open resection of colorectal cancer. Dig Surg 2014; 31: 161-8.

27. Kvehaugen AS, Farup PG. Changes in gastrointestinal symptoms and food tolerance 6 months following weight loss surgery: associations with dietary changes, weight loss and the surgical procedure. BMC Obes 2018; 5: 29.

28. Goldenshluger M, Goldenshluger A, Keinan-Boker L, et al. Postoperative outcomes, weight loss predictors, and late gastrointestinal symptoms following laparoscopic sleeve gastrectomy. J Gastrointest Surg 2017; 21: 2009-15.

29. Johanson JF, Lafferty J. Epidemiology of fecal incontinence: the silent affliction. Am J Gastroenterology 1996; 91: 33-6.

30. Ihnát P, Kozáková R, Ihnát Rudinská L, et al. Fecal incontinence among nursing home residents: is it still a problem? Arch Gerontol Geriatr 2016; 65: 79-84.

31. Whitehead WE, Borrud L, Goode PS, et al. Fecal incontinence in US adults: epidemiology and risk factors. Gastroenterology 2009; 137: 512-7.

32. Fysekidis $M$, Bouchoucha $M$, Bihan $\mathrm{H}$, et al. Prevalence and co-occurrence of upper and lower functional gastrointestinal symptoms in patients eligible for bariatric surgery. Obes Surg 2012; 22: 403-10.

33. Markland AD, Goode PS, Burgio KL, et al. Incidence and risk factors for fecal incontinence in black and white adults: a population based study. J Am Geriatr Soc 2010; 58: 1341-6. 
34. Nelson RL. Epidemiology of fecal incontinence. Gastroenterology 2004; 126: S3-7.

35. Stefanidis D, KuwadaTS, Gersin KS. The importance of the length of the limbs for gastric bypass patients - an evidencebased review. Obes Surg 2011; 21: 119-24.

36. Ait Said K, Leroux Y, Menahem B, et al. Effect of bariatric surgery on urinary and fecal incontinence: prospective analysis with 1-year follow-up. Surg Obes Relat Dis 2017; 13: 305-12.

37. Scozzari G, Rebecchi F, Giaccone C, et al. Bariatric surgery improves urinary incontinence but not anorectal function in obese women. Obes Surg 2013; 23: 931-8.

38. Lee Y, Yu J, Tikkinen KAO, et al. The impact of bariatric surgery on urinary incontinence: a systematic review and meta-analysis. BJU Int 2019 May 28. doi: 10.1111/bju.14829 [Epub ahead of print].

39. Gero D, Steinert RE, le Roux CW, Bueter M. Do food preferences change after bariatric surgery? Curr Atheroscler Rep 2017; 19: 38.

40. Coluzzi I, Raparelli L, Guarnacci L, et al. Food intake and ganges in eating behavior after laparoscopic sleeve gastrectomy. Obes Surg 2016; 26: 2059-67.

41. Ammon BS, Bellanger DE, Geiselman PJ, et al. Short-term pilot study of the effect of sleeve gastrectomy on food preference. Obes Surg 2015; 25: 1094-7.

42. Murphy R, Tsai P, Jullig M, et al. Differential ganges in gut microbiota after gastric bypass and sleeve gastrectomy bariatric surgery vary according to diabetes remission. Obes Surg 2017; 27: 917-25.

43. Damms.Machado A, Mitra S, Schollenberger AE, et al. Effects of surgical and dietary weight loss therapy for obesity on gut microbiota composition and nutriet absorption. Biomed Res Int 2015: 2015: 806248.

44. Melissas J, Leventi A, Klinaki I, et al. Alterations of global gastrointestinal motility after sleeve gastrectomy. Ann Surg 2013; 258: 976-82.

45. Trung VN, Yamamoto H, Furukawa A, et al. Enhanced intestinal motility during oral glukose tolerance test after laparoscopic sleeve gastrectomy: preliminary results using cine magnetic resonance paging. PLoS One 2013; 8: e65739.

46. Pellitero S, Martínez E, Puig R, et al. Evaluation of vitamin and trace element requirements after sleeve gastrectomy at long term. Obser Surg 2017; 27: 1674-82.

47. Shah HN, Bal BS, Finelli FC, et al. Constipation in patiens with thiamine deficiency after Roux-en-Y gastric bypass surgery. Digestion 2013; 88: 119-24.

48. Tang L, Alsulaim HA, Canner JK, et al. Prevalence and predictors of postoperative thiamine deficiency after vertical sleeve gastrectomy. Surg Obes Relat Dis 2018; 14: 943-50.

Received: 26.09.2019, accepted: 18.10.2019. 